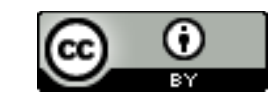

Esta obra está sob o direito de Licença Creative Commons Atribuição 4.0 Internacional.

\title{
A INCLUSÃO DA TECNOLOGIA NA EDUCAÇÃO INFANTIL PARA ALUNOS COM DEFICIÊNCIA
}

Maria das Dores Soares Slva 1

Amara Maria de Lima Buarte ${ }^{2}$

Audeluze Maria Araújo Victor De Mendonça Lopes ${ }^{3}$

Elizabeth Calheiros Borges ${ }^{4}$

Lucineide Maria de Jesus Santos 5

Iriscleiti da Silva França6

\section{RESUMO}

O presente artigo traz como enfoque mostrar a inclusão da tecnologia na educação infantil com alunos especiais, sob uma perspectiva de melhorar o conhecimento da criança da pré-escola, através de pesquisa bibliográfica. Para tanto, abordaremos como essas inovações estão contribuindo para informar os discentes e docentes incluí-los no mundo digital, deve ser compreendida como responsabilidade social compartilhada. Com objetivo de assegurar a igualdade de oportunidade, e a construção de ambientes acessíveis e a ampla inclusão de crianças. "O artigo refaz um caminho no qual a infância e a criança são percebidas em sua dimensão singular", de modo a recuperar, no fim do percurso, em um caráter plural que as noções de criança e infância encerram. A principal contribuição deste artigo é apresentar encaminhamentos para a incluir as tecnologias para crianças especiais no ensino infantil.

Palavras - Chave: Tecnologias. Inclusão. Educação. Ensino Infantil.

\footnotetext{
${ }^{1}$ dr.csbarros@hotmal.com.

2 amarabuarque@ hotmail.com

${ }^{3}$ Del.fest@hotmail.com

${ }^{4}$ bethcalheirosborges@gmail.com

5 lucineidealagoas@hotmail.com

6 iriscleiti@gmai.com
} 


\section{INTRODUÇÃO}

A educação é uma prática social que existe em toda e qualquer sociedade humana, em todos os lugares, desde o momento em que essas sociedades, ao produzirem símbolos e normas, acharam por bem transmitir essa produção às novas gerações. Um erro gravíssimo cometido ao longo da história da humanidade foi o de excluir quem era portador de alguma deficiência física, e isso nas últimas décadas tem sido modificado. Com condições dignas de acesso é um direito defendido por lei (JUNQUEIRA, 2012).

Então uma escola infantil para o nosso tempo, foco exagerado no consumo, falta de tempo, novas configurações familiares, crianças com necessidades especiais. São tantos os desafios apresentados na sociedade atual. Que muitas vezes os pais e professores sentemse inseguros diante da tarefa de educar as crianças e com um cuidado maior com as que possuem limitações físicas (FARRELL, 2008).

Com tudo em educação, não há respostas prontas, mas ideias e propostas que podem sugerir alternativas, contribuindo para as discussões que a escola que a escola de educação infantil precisa travar uma luta com a complexidade do mundo atual, a necessidade de mais tempo para viver o cotidiano. Segundo Sarmento (2008) “a educação infantil inclusiva é chamada a responder ás necessidades decorrentes dos mundos complexos em que vivem as crianças, na sua diversidade e na sua alteridade". Tratase, sem modelos pré-formatados, de atualizar a sua missão na mutável realidade social.

Deve ser compreendida como responsabilidade social compartilhada, visando assegurar a igualdade de oportunidades, a construção de ambientes acessíveis e a ampla inclusão sociocultural. As cidades, as escolas, os ambientes públicos, coletivos e de lazer, os serviços de saúde, os meios de transportes, as formas de comunicações e informações devem ser pensadas de modo a facilitar a convivência e a participação de todos os cidadãos em iguais condições de direitos, nos vários aspectos da vida diária das comunidades (BARBOSA, 2006). 


\section{METODOLOGIA}

Este estudo é uma pesquisa bibliográfica, onde a busca dos artigos a serem analisados foi realizada nas bases de dados BVS, Scielo e Google Acadêmico. A escolha dessas bases de dados justificou-se por ser gratuita e de livre acesso e também pela crescente relevância que o Google vem adquirindo na difusão da produção acadêmica (DINIZ, 2012).

\section{A relevância da inclusão na alfabetização}

Para que a inclusão realmente aconteça, é necessário garantir diversos recursos à parceria entre $\mathrm{o}$ atendimento educacional especializado (AEE)e os docentes, o amparo das famílias e o investimento em acessibilidade que beneficie as crianças especiais. Por sua trajetória histórica de não atendimento do aluno com deficiência, a escola comum não está preparada para tal tarefa, ou seja, nossa escola não é inclusiva e não sabe ser, o que significa que sua transformação no sentido de cumprimento legal e de responder positivamente aos anseios sociais, requer alterações em toda a sua dinâmica. Essas alterações envolvem vários aspectos: estruturais, econômicos, instrumentais, de recursos humanos, pedagógicos etc. (MENDES, 2010).

A construção da escola inclusiva desde a educação infantil implica em pensar em seus espaços, tempos, profissionais, recursos pedagógicos etc. voltados para a possibilidade de acesso, permanência e desenvolvimento pleno também de alunos com deficiências, alunos esses que, em virtude de suas particularidades, apresentam necessidades educacionais que são especiais. Talvez o maior desafio esteja na prática pedagógica. Embora todos os aspectos mencionados sejam fundamentais e estejam atrelados uns aos outros, a ação pedagógica direcionada e intencional contribuirá em muito para a inclusão em seu sentido pleno (PRETTO,1996).

Hoje o mundo globalizado possibilita um entendimento social inclusivo com inúmeras possibilidades de transformação e criações inovadoras. A mudança é uma ação complicada porque, tendo como objetivo melhorar a vida das pessoas pode estar a pôr em conflito as suas crenças, estilos de vida e comportamentos. Para que essa mudança seja efetiva, é necessário compreender a forma como os indivíduos envolvidos vivenciam a sua situação e implicá-los nessa mesma mudança, pois são eles que vão viver com ela (BARBOSA, 2006).

Segundo Strasburger (2011) acresce que a ação educativa com crianças é sempre realizada por profissionais que também foram crianças. Porém, foram crianças em outro tempo, em outras circunstâncias 
históricas e, geralmente em outras condições sociais. Existe uma relação de alteridade entre adultos e a criança, para tanto, temos de caracterizar as condições sociais que marcam as possibilidades de vida na atualidade e que, sendo comuns a todas as gerações, têm especificidades no que se diz respeito às crianças especiais.

O tempo é o articulador da vida, é ele que corta, amarra ou tece a vida. É o tempo que nos evidencia que temos um passado em comum, que temos uma memória e uma história, que é preciso compreender esse passado e compartilhar a experiência do presente para, assim, propor possibilidades para o futuro. De acordo com Barbosa (2006) é o tempo que nos oferece a dimensão de continuidade, de durabilidade, de construção de sentido para a vida, seja ela pessoal ou coletiva para melhorar incluir na sala do ensino infantil.

Como no mundo é regulado por regras, é preciso ter clareza sobre quais são os limites para que a criança especial possa experimentar essas regras, buscando construir com autonomia sua identidade e suas possibilidades de interação com o meio em que está inserida (FARRELL, 2008).

\section{Inclusão e educação infantil como parceiras}

A LDB define a educação infantil como primeira etapa a educação básica que tem como finalidade o desenvolvimento integral da criança até seis anos de idade, em seus aspectos físico, psicológico, intelectual e social.Considerando a proposta de educação inclusiva opção brasileira referendada em suas políticas educacionais, entendemos que o movimento de reorganização da escola tem que começar na educação infantil por ser esta, conforme prescrito na lei, a primeira etapa da educação (JUNQUEIRA, 2012).

Interessa, pois, não apenas melhorar a qualidade da educação escolar, mais melhorá-la de modo equitativo (CURY, 2005). Em outros termos fazem-se necessárias ações, sobretudo mediante políticas públicas consistentes e focalizadas, que beneficiem os grupos menos favorecidos inclusive as crianças especiais. Como no mundo tudo é regulado por regras, é preciso ter clareza sobre quais são os limites para que a criança possa experimentar essas regras, buscando construir com autonomia sua identidade e suas possibilidades de interação com o meio em que está inserida (MENDES, 2010)

A criança se insere, atualmente, no sistema educacional cada vez mais cedo. Muitas das mudanças referidas foram provocadas por uma maior participação feminina no mercado de trabalho, alterando a rotina de cuidados e a educação dos filhos. Esse fato é relacionado com a criação das creches. Nesse sentido, a creche estava 
sempre associada a um caráter assistencialista e se preocupava apenas com a alimentação, a higiene e a segurança física. (PRETTO,1996).

Portanto, o modelo de Educação Infantil tem sido alterado à medida que a concepção de educação da criança de 0 a 6 anos atinge objetivos diferenciados, com propostas educacionais explícitas fundamentadas em teorias psicológicas do desenvolvimento infantil. Acriança nessa idade passa a ser vista como sujeito de educação, com necessidade de atendimento qualificado que vise o seu desenvolvimento integral sendo ela capaz de aprender (BARBOSA, 2006).

De acordo com Pozo (2002) "a escola infantil deve proporcionar o cenário para que a criança compreenda melhor como percebe o mundo e como acredita que as coisas acontecem", o trabalho do docente deve ser direcionado a guiar a exploração das crianças e suas explicações sobre o q observam.

Educação de qualidade para todos, pode parecer uma bandeira já desbotada pelo uso excessivo, mas quem conhece o dia-a-dia das escolas de ensino infantil ela vem buscando incluir todos os alunos de forma igual e acolhedora. Nesse sentido a educação infantil se propõe em gera cidadãos mais cuidadosos responsáveis e comprometidos, capazes de contribuir para um mundo mais justo e pacifico, deve começar na primeira infância, uma vez que valores, atitudes, comportamentos e habilidades adquiridas nesse período podem ter impacto duradouro na vida (PRETTO,1996).

Toda criança tem direito que assegurar acesso à educação e ao cuidado infantil de qualidade para todas as crianças é uma pré-condição importante para a melhoria do desenvolvimento educacional. A primeira infância abrange o período em que as bases do desenvolvimento são lançadas e deve ser percebida como o primeiro estágio de educação, o qual deve ser acessível assim como o ensino fundamental (JUNQUEIRA, 2012).

\section{Aportes da tecnologia na educação infantil}

Estamos envoltos em um ecossistema comunicativo; por isso, a escola deve absorver a ideia de que é preciso incorporar um trabalho sério, que contemple o novo. A escola tem que aproveitar essas tecnologias em favor de todos, levando-se conta uma perspectiva crítica para sua utilização, compreendendo realmente o sentido de todas essas informações e consigam utiliza-la de forma correta, aplicando e transformando e buscando possibilidades pedagógicas com o uso das tecnologias, aponta para o futuro das práticas docentes, discutindo as novas 
perspectivas pedagógicas é os desafios ao professor (BARBOSA, 2006).

Entendemos que o docente precisa usar essas novas tecnologias para auxiliar suas aulas de forma prazerosa e eficaz. Onde o aluno especial possa conhecer e utilizar essas tecnologias e para que isso possa acontecer é preciso olhar a educação de um modo diferente. De acordo com Gomes (2013) "para entender a relação entre a infância e a tecnologia é necessário resgatar $o$ ato de brincar enquanto experiência lúdica”. Sabe-se que é um grande desafio inclui as tecnologias no setor educacional, mas essas tecnologias as de comunicação tem o objetivo de mostrar a realidade da sociedade e uni a escola às novas tecnologias (FARRELL, 2008).

De acordo com Rezende (2002) as novas tecnologias não implicam novas práticas pedagógica nem vice-versa aparentemente poderíamos dizer que não há relação entre essas duas instancias. Entretanto, isso não é necessariamente verdade, se consideramos que o uso das novas tecnologias pode contribuir para novas práticas pedagógicas desde que seja baseado em novas concepções de conhecimento, de aluno, de professor, transformando uma série de elementos que compõem o processo de ensinoaprendizagem (JUNQUEIRA, 2012).
Que as novas tecnologias sejam utilizadas para melhorar o processo educacional, buscando assim benefícios de ensinar alguns conteúdos para melhor fixação do conhecimento para com o aluno especial. Mais vale ressaltar que não devese fazer dessas tecnologias o único instrumento para execução dessas aulas e sim um auxílio para a pratica do professor e atendendo as necessidades dos educandos, saindo assim do tradicional para a modernidade com o avanço incontrolável das novas tecnologias de informação e comunicação, possibilitará a inclusão das crianças especiais com a tecnologia (SANTOS, 2005).

Acredita-se que a melhora da educação tem uma parceria com as novas tecnologias com o acesso mais fácil as mídias, e os profissionais da educação tem que ser um facilitador de repasse de conhecimento e reconhecer o potencial dessas tecnologias e criar desafios educativos para esses alunos. No entanto, ainda têm educadores que tem certo receio em utilizar essas novas tecnologias como instrumentos de aula. Nesse contexto vivese um momento impar da inclusa das novas tecnologias na escola, propiciando sua utilização de forma dinâmica e buscando igualdade de oportunidade para todos, todos esses fatores irão favorecem a melhoria da 
educação de uma forma ampla e eficaz

(MENDES, 2010).

\section{CONSIDERAÇÕES FINAIS}

No entanto, foi visto que são grandes as dificuldades de inclusão no ensino infantil. A educação se baseia necessariamente na garantia do direito à educação de qualidade para todos inclusive as crianças. Pôde-se constatar a importância da pré- escola no desenvolvimento intelectual das crianças.

Faz-se necessária uma adaptação da escola para a evolução das crianças. A relação como se aprende e como se ensina deve ser repensada, tem que ter muito cuidado na hora de se passar conteúdo aos alunos da pré-escola. É preciso que a sala de aula seja um espaço agradável, confortável e motivante para os alunos onde eles possam utilizar para melhorar o ensino aprendizagem, sabendo que, estamos distante desta realidade, mais muito já foi feito para a ingressão do ensino infantil na grade curricular de ensino.

\section{REFERÊNCIAS}

BARBOSA, M. C. S. Por amor e por força: rotinas na educação infantil. Porto Alegre: Artmed, 2006.

CURY, Carlos Roberto Jamil. Politicas inclusivas e compensatórias na educação básica. Caderno de pesquisa, São Paulo, v 35, n.124, p. 11-32, jan./abr.2005.
A escola se apresenta como direcionadora e informadora diante das adversidades da vida educacional, que continua mesmo fora da escola. Sendo assim, esse é um modelo educacional muito interessante para ser estudado a fim de que possa gerar ideias e subsídios não apenas para o seu aperfeiçoamento, mas, principalmente, contribuir para a construção de novas propostas para a educação infantil nas escolas públicas do País para com isso diminui as dificuldades do ensino-aprendizagem.

A discussão de uma educação para os direitos humanos deve destacar a necessidade de implantação de projetos que iram auxiliar o ensino na pré-escola, e com isso melhorar a aprendizagem das crianças. É com estas considerações acima que vemos em momento de grande inspiração literária entregando-se a uma nova época que envolve o ensino infantil e a inclusão de alunos especiais em nossas escolas.

FARRELL, M. Estratégias educacionais em necessidades especiais: dificuldades de comunicação e autismo. Porto Alegre: Artmed, 2008.

GOMES, Suzana dos Santos. Brincar em tempos digitais. Minas Gerais, v.19, n.113, p.46, set/out. 2013.

JUNQUEIRA, Eduardo S, Educação e novas tecnologias. Presença Pedagógica, 
julho/agosto v.18/n.106. Editora

Dimensão, 2012.

MENDES, E. G. Inclusão marco zero:

SANTOS e no M, Yracy de Sousa. As

começando pelas creches. Araraquara, SP:

Novas Tecnologias na Educação e seus

Junqueira \& Marin, 2010.

POZO, J, L. Aprendizes e mestres: a nova cultura da aprendizagem, Porto Alegre:

Artmed, 2002.

PRETTO, Nelson. Uma Escola/com

futuro. Rio de Janeiro; Papirus. 1996.

REZENDE, Flavia. As Novas Tecnologias na Pratica Pedagógica Sob a Perspectiva Construtivista. Ensaio-Pesquisa em Educação em Ciências V.02 N.1. Rio de Janeiro RJ. Março. 2012.

Reflexos na Escola e no mundo do

Trabalho. II jornada internacional de políticas pública. São Luís. MA. 2005.

SARMENTO, M. J. Construir a educação infantil. Pátio: educação infantil. Artmed. Ano X, No32, julho/setembro, 2012.

STRASBURGER, V. C.; WILSON, B. J. JORDAN, A.B. Crianças, adolescentes e a mídia. Porto Alegre: Penso 2011. 